\title{
An audit of training in public health medicine
}

\author{
Elizabeth Rous', Margaret Guy², Peter Hayward ${ }^{3}$ and Peter Bramleby ${ }^{4}$
}

\author{
${ }^{1}$ Trent Regional Health Authority, ${ }^{2}$ East Anglian Regional Health Authority, ${ }^{3}$ South West Thames \\ Regional Health Authority and ${ }^{4}$ South East Thames Regional Health Authority, UK
}

\begin{abstract}
Summary: Postgraduate training is one of the core functions of every speciality. The Trainee Members Committee of the Faculty of Public Health Medicine audited the quality of training in public health medicine according to guidelines set by the Education Committee of the Faculty. The survey identified several weaknesses in training which need to be remedied by Faculty Members. This audit model would prove useful to other specialties and the benefit of trainee involvement in the Committee structure of the Faculty is highlighted.
\end{abstract}

\section{Introduction}

Postgraduate training of junior medical staff is one of the core functions of every specialty. Better training is likely to lead to increased quality of practice. The Royal Colleges and their Faculties have a duty to set guidelines for training and to inspect training posts. ${ }^{1}$ The audit described in this paper was based on guidelines set by the Faculty of Public Health Medicine. Audit is not an end in itself; it should lead to change in professional practice. In this instance, the desired change was an improvement in the quality of training in public health medicine. Usually, the audit cycle begins with the setting of standards, moves on to the observation of practice, to recommendations for improvement and ultimately to the implementation of change, before starting again by reviewing the standards. ${ }^{2}$ The purpose of this survey was to perform stage two of the cycle, the observation of practice. It must be noted however, that the necessary infrastructure within the Faculty was already in place allowing the final stages of the cycle to be undertaken and the audit loop to be completed. This structure is described in the second paragraph of the background section below.

\section{Background}

Public health medicine training usually commences at registrar level after trainees have completed a minimum of two years post-registration clinical

Correspondence: E. Rous, M.R.C.G.P., Department of Public Health Medicine, North Western Regional Health Authority, Gateway House, Piccadilly South, Manchester M60 7LP, UK

Accepted: 23 September 1991 experience. Training schemes are organized on a Regional basis in England and within Health Boards in Scotland, Wales, Northern Ireland, the Defence Medical Services, the Department of Health and the Communicable Disease Surveillance Centre also run training schemes. Academic training for Part I of the Membership of the Faculty of Public Health Medicine (MFPHM) ( written examination) is either in the form of a M.Sc. course or integrated with in-service training The Part II examination involves the submission of a portfolio of reports on work undertaken during training and a viva on general public health topics.

Since its inauguration in 1972, as the Faculty of Community Medicine, the Faculty has encouraged involvement of trainees in the arrangements for their own training. Each Region or country elects a trainee to the Trainee Members Committee, whose chairperson sits as an observer on the Faculty Board. There is also representation on other Faculty Committees. This system enables effective communication between the Faculty and its trainees. Thus, when the Trainee Members Committee decided to conduct the training survey, it was in a position to achieve a high response rate and to take its findings to key policy-making committees of the Faculty.

In July 1989, the Education Committee of the Faculty drew up recommendations which defined the standards expected of training schemes in the UK. These related to the structure and process of training. The key recommendations are summarized in the Appendix.

\section{Method}

The Trainee Members Committee set up a small working group to carry out the survey, which 
defined the following objectives:

i) to collect descriptive data on trainees and training locations, and

ii) to identify strengths and weaknesses in training programmes.

A questionnaire was distributed by members of the Trainee Members Committee to all doctors in training posts in public health medicine within the UK. The questions were based on the Education Committee's Recommendations and were piloted amongst members of the Committee. The data were analysed using Epiinfo, a computerized database produced by the Centers for Disease Control, Atlanta, Georgia, USA.

\section{Results}

\section{Response rates}

The questionnaire was sent to 387 trainees in 143 training locations and the response rate was $89 \%$ (345 trainees).

\section{Rotations}

Most trainees (303) had been offered a rotation during their training.

\section{Training policies and induction courses}

Only 106 trainees $(32 \%)^{\dagger}$ were aware of a training policy within their training scheme. Eighty-six trainees thought there was no policy and $141 \mathrm{did}$ not know whether a training policy existed. One hundred and twenty trainees $(35 \%)^{\dagger}$ did not have an induction course at the start of training.

\section{Assigned service trainers and academic tutors}

Sixteen trainees $(5 \%)^{\dagger}$ did not have an assigned service trainer and this was not explained by attendance on a full-time M.Sc. course at the time of the survey. One hundred and twenty-four trainees $(36 \%)^{\dagger}$ did not have an assigned academic tutor and 52 of these $(41.5 \%)$ were at the crucial stage of preparing a written submission for the Part II of the MFPHM examination.

\section{Lone trainees}

There were 58 lone trainees, 11 of whom were in their first year of training.

$\dagger$ Percentage refers to the total number of trainees answering the question.

\section{Time spent with trainers and levels of supervision}

One hundred and eighty-eight trainees $(57 \%)^{\dagger}$ were spending at least half an hour per week or more of protected time with their trainer. The remainder (43\%) were spending less than half an hour a week. Respondents spending more than half an hour a week with their trainer were more likely to feel they were given enough time. Two hundred and ninetytwo trainees $(85 \%)^{\dagger}$ were able to see their trainer without a pre-arranged appointment but only 176 trainees $(52 \%)^{\dagger}$ felt that the level of supervision they received was appropriate. A substantial minority of trainees (40) felt that their level of supervision was negligible or barely adequate. The number of trainees per trainer bore no relation to either the level of supervision received or whether the amount of protected time spent with the trainer per week was sufficient.

\section{Trainer development}

Less than $50 \%$ (139) of trainees thought that their trainer had attended a Trainer Development Course as recommended by the Faculty. However, most trainees thought that the needs of their trainers for continuing education were being met.

\section{Learning contracts}

The percentage of trainees with learning contracts varied considerably among training schemes $(\text { range }=0.90 \% \text {, mean }=32 \%)^{\dagger}$.

\section{Facilities at training locations}

Two hundred and fifty-seven trainees $(75 \%)^{\dagger}$ had a quiet office, with easy access to a phone, photocopying and typing. Particular problems were reported with secretarial and clerical support for message taking, diary keeping and filing maintenance. Trainees were more likely to have access to computers than secretarial support, with half having a full range of software packages. However, the fact that only 254 trainees $(74 \%)^{\dagger}$ had access to a library with core reference texts was a cause for concern.

\section{Recommendations}

As a result of the survey findings, recommendations were made for improving training in public health medicine. These were divided into key points for different groups of Faculty members. Faculty Advisers were asked to ensure that a written training policy for their scheme was produced and publicized, that all trainees had an assigned service trainer and academic tutor, and that all training 
locations were visited at least once every two years.

Trainers were asked to ensure that adequate induction programmes were arranged for new appointees, to spend at least half an hour per week of protected time with each trainee on a one-to-one basis, and to agree a written framework for learning, such as a learning contract, with each trainee. It was suggested that all trainers should participate in trainer development activities and ensure that the physical aspects of the training location met trainees' needs. Trainees were advised to acquaint themselves with their local training policy and to take the initiative in ensuring that their training needs were being met. The Trainee Members Committee allotted itself the task of clarifying the terms 'training policy', 'learning contract' and 'induction programme'.

\section{Implementation}

Preliminary results were presented to the Annual Faculty Training Conference in March 1990. Subsequently, a more detailed report was circulated to all trainees, Faculty Advisers, the Education Committee and the Faculty Board. A summary of the results has been published in the Faculty newsletter.

In future the survey will be repeated annually so that the progress on recommendations of successive surveys can be monitored. The questionnaire will be modified as necessary to collect data on topical training issues.

\section{Discussion}

Many of the recommendations of the survey can be implemented through an increased commitment to training by all Faculty members. However, it must be recognized that the recent increase in recruitment to the specialty, although most welcome, is putting added pressure on the stretched resources of both service and academic departments. There is a shortage of experienced trainers which is only likely to be resolved in the long term. In the meantime every public health doctor needs to make training their top priority and to ensure that resources are directed towards addressing the survey recommendations.
The recognition that doctors in training are mature graduates with a clear idea of their training needs has strengthened the specialty of public health medicine. In particular, the benefits of trainee involvement in the standard setting body cannot be over-emphasized. Trainee representation on the Faculty Board will ensure that the recommendations of the survey are placed towards the top of the Faculty's agenda. Also, the Trainee Members Committee proved to be vital to the distribution of the survey and the dissemination of the results. The Annual Training Conference acted as an open forum for discussing training standards and the holding of such an event is recommended to others. In addition, the Faculty Adviser network provided a channel for the results to be disseminated to trainers and discussed at a Regional level. It would have been difficult to perform the audit cycle described without such a framework in place.

This particular survey shows that the audit of postgraduate training is possible. Other specialties may wish to use this model for auditing of training, accepting that surveys and the setting up of the supportive infrastructure cost time and money. This particular survey absorbed at least 250 hours of medical and clerical time. However, such time is well spent if it leads to an improvement in professional practice for the following decades.

\section{Conclusions}

Training in public health medicine has room for improvement. This audit of training performed by the Trainees Members Committee of the Faculty of Public Health Medicine has highlighted a number of common weaknesses which can be improved. Other specialties may wish to follow elements of this model, not least the support structure which enables standards to be set, assessment to be made, findings to be discussed and improvements to be implemented.

\section{Acknowledgements}

We would like to thank all the trainee representatives on the Trainee Members Committee for the distribution and collection of the questionnaire. Dr Rous would like to thank her trainer, Dr Stephen Whitehead for his support during the performance of this audit.

\section{References}

1. General Medical Council: Education Committee. Recommendations on the training of specialists. (1987).

2. Faculty of Public Health Medicine. Report of a working group on audit in Public Health Medicine. (1989). 


\section{Appendix}

Summary of recommendations for specialist training in public health medicine

1. Each trainee should be provided with an identified service trainer and an identified academic tutor.

2. Trainees should receive a variety of training experiences through attachments to different training bases.

3. Departments should have an agreed training policy and run an induction programme for newly placed trainees.

4. At least for their first year in post, a new registrar should not be the sole trainee in the department.

5. The trainer should show a commitment to training as exhibited by:

a) being available for at least one hour per week of protected contact time with each trainee; b) regular attendance at relevant events including trainer development activities and Faculty training conferences;

c) the use of a written framework for training, such as a learning contract;

d) the ability to strike a balance between supervision, delegation and collaboration.

6. A training location should provide:

a) a quiet office space with desk, filing cabinet and shelves situated within the department of Public Health Medicine;

b) exclusive use of a telephone extension with the facility to dial outside numbers directly;

c) photocopying facilities;

d) secretarial services;

e) a microcomputer with appropriate software;

f) access to rooms for meetings;

g) access to a library with core reference books and journals. 